\title{
Glucocorticoid receptor and Klf4 co-regulate anti-inflammatory genes in keratinocytes
}

Lisa M. Sevilla ${ }^{1}$, Víctor Latorre ${ }^{1,2}$, Elena Carceller ${ }^{1}$, Julia Boix $^{1}$, Daniel Vodák ${ }^{3}$, Ian Geoffrey Mills $^{4,5,6}$, and Paloma Pérez ${ }^{1}$

${ }^{1}$ Instituto de Biomedicina de Valencia-Consejo Superior de Investigaciones Científicas (IBVCSIC), Jaime Roig 11, E-46010 Valencia, Spain.

${ }^{2}$ Faculty of Human and Medical Sciences, The University of Manchester, Manchester UK

${ }^{3}$ Bioinformatics Core Facility, Institute for Cancer Genetics and Informatics, The Norwegian Radium Hospital, Oslo University Hospital, Norway

${ }^{4}$ Prostate Cancer Research Group, Centre for Molecular Medicine (Norway), University of Oslo and Oslo University Hospitals, Oslo, Norway

${ }^{5}$ Department of Cancer Prevention, Oslo University Hospitals, Oslo, Norway.

${ }^{6}$ Department of Urology, Oslo University Hospitals, Oslo, Norway.

Corresponding autor and person to whom reprint requests should be addressed:

Paloma Pérez, $\mathrm{PhD}$

Instituto de Biomedicina de Valencia-Consejo Superior de Investigaciones Científicas (IBV-

CSIC)

Jaime Roig 11, E-46010, Valencia, Spain

Phone: +34-96-339-1766

Fax: +34-96-369-0800

e-mail: pperez@ibv.csic.es

Grants and fellowships supporting the writing of paper: SAF2011-28115 of the Ministerio de Economía y Competitividad from the Spanish government. EC and JB are recipients of FPU and FPI fellowships of the Spanish Ministery, respectively

Disclosure Statement: The authors have nothing to disclose. 


\section{Abstract}

The glucocorticoid (GC) receptor (GR) and Kruppel-like factor Klf4 are transcription factors that play major roles in the skin homeostasis by regulating the expression of overlapping gene subsets. However, whether these transcription factors cooperate in binding genomic regulatory regions in epidermal keratinocytes was not known. Here, we show that in dexamethasonetreated keratinocytes GR and Klf4 are recruited to genomic regions containing adjacent GR and KLF binding motifs to control transcription of the anti-inflammatory genes Tsc22d3 and Zfp36. GR- and Klf4 loss of function experiments showed total GR but partial Klf4 requirement for full gene induction in response to dexamethasone. In wild type keratinocytes induced to differentiate, GR and Klf4 protein expression increased concomitant with Tsc22d3 and Zfp36 up-regulation. In contrast, GR-deficient cells failed to differentiate or up-regulate Klf4 and Zfp36 correlating with increased expression of the epithelium-specific Trp63, a known transcriptional repressor of Klf4. The identified transcriptional cooperation between GR and Klf4 may determine cell-type specific regulation and have implications for developing therapies for skin diseases.

Key words: glucocorticoid receptor, Kruppel-like factor 4, keratinocyte, transcription, inflammation. 


\section{Introduction}

Glucocorticoid (GC) hormones act through the GC receptor (GR), a ligand-dependent transcription factor (TF) that regulates gene expression in virtually all cell types. The mechanisms of GR action include transactivation, direct binding to GC responsive element (GRE)-containing genes; and transrepression, interference with other transcription factors through protein-protein interactions $(1,2)$. GR can also repress gene expression by directly binding to recently identified simple negative GREs and recruiting transcriptional corepressors (3). GR controls a vast array of physiological processes including modulation of the inflammatory response, as well as epidermal differentiation and homeostasis $(2,4)$. Identifying mechanisms for the tissue-specific actions of GR is of great interest due to the widespread use of GCs as therapeutic agents, such as in inflammatory skin diseases, where prolonged usage results in undesirable side effects, including skin thinning and delayed wound healing $(1,4)$.

Combinatorial action of GR with cell type-specific TFs is a way to attain diverse physiological outcomes (5). While the majority of ligand-bound GR associates with pre-existing sites of open chromatin (6), it can also bind to transcriptionally silent chromatin acting as a "pioneer factor" (7). GR binding has been shown to facilitate the binding of other TFs via "assisted loading", a process whereby GR-dependent recruitment of chromatin remodeling proteins change local nucleosome structure creating a more accessible state (8).

The Krüppel-like family of transcription factors (KLF) is formed by a class of DNAbinding proteins with a key role in development and physiology. KLF family members are known to functionally interact with other members of the nuclear hormone receptor superfamily, in a tissue specific fashion (9). Klf4 is critical for function of differentiated epithelial cells consistent with its high expression in the epidermal suprabasal layers (10). Klf4 is also one of the four factors that reprogram differentiated cells to pluripotency (11). How Klf4 is capable of regulating such diverse processes is not completely understood. Along these lines, a recent study in human keratinocytes demonstrated that Klf4 forms a complex with the epithelial-specific TF ZNF750 and chromatin regulators RCOR1 and CTBP1/2 to promote transcription of genes associated with terminal differentiation (12). 
Genetic experiments established that both GR and Klf4 are critical for establishing the skin's barrier function. For instance, mice deficient in the expression of either Klf4 or GR have defective epidermal differentiation and permeability barrier acquisition $(13,14)$. Antenatal GC injections accelerate in utero barrier formation as does epidermal (keratin 5 (K5) promoter) overexpression of Klf4 $(15,16)$. The observation that GC treatment of developing K5-Klf4 mice further accelerated formation of the epidermal barrier suggested synergistic actions of GR and Klf4 (17). Further evidence for synergism was the identification of a gene subset similarly regulated by GC treatment or Klf4 overexpression (17). However, direct co-regulation of keratinocyte gene expression has not been demonstrated, in part due to the absence of a suitable model to evaluate GR-mediated gene regulation $(14,17)$. This has been recently overcome by the generation of GR epidermal knock-out $\left(\mathrm{GR}^{\mathrm{EKO}}\right)$ mice in our group (18). Newborn $\mathrm{GR}^{\mathrm{EKO}}$ epidermis showed aberrant expression of genes involved in epidermal barrier function, innate immunity and inflammation, many of which are also deregulated in inflammatory skin diseases, such as atopic dermatitis and psoriasis (18). These data suggest that GR may be a link between defective epidermal differentiation and inflammation during development.

In postnatal skin, the role of GR and Klf4 has been evaluated using gain or loss of function models restricted to K5 or K14 expressing tissues. In the case of GR, overexpression results in resistance to epidermal inflammation and tumorigenesis $(4,19)$, while loss provokes an increased sensitivity to inflammatory stressors and skin carcinogenesis $(18,20)$. Likewise, inducible deletion of Klf4 in the epidermis results in increased DMBA/TPA induced tumorigenesis (21). Inducible activation of Klf4 in the epidermal basal layer unexpectedly resulted in epithelial dysplasia (22), though this discrepancy may be due to the fact that depending on cellular context Klf4 can act as a tumor suppressor or oncogene (23).

In this study, we present evidence demonstrating that GR and Klf4 are recruited to GCand KLF-responsive elements on a subset of GC-regulated genes to modulate transcription in keratinocytes. Both TFs bind to regions near the anti-inflammatory genes Tsc22d3 and Zfp36, and cooperate in their regulation. Furthermore, we found that Tsc22d3 and Zfp36 are upregulated during keratinocyte terminal differentiation, suggestive of a link between regulation of 
inflammatory processes and terminal differentiation, or of novel roles for these genes in keratinocytes. As Klf4 is enriched in epithelial cells, it is conceivable that GR preferentially uses the GR binding sites (GBSs) adjacent to KLF sites in keratinocytes as a mechanism determining cell-type specific regulation. 


\section{Materials and Methods}

\section{Reagents and antibodies}

Unless otherwise specified all chemicals are from Sigma-Aldrich. Primary antibodies used were specific for GR (sc-1004), Klf4 (sc-20691), p63 (sc-8431, Santa Cruz Biotechnology), phosphoGR Ser 211 (4161S, Cell Signaling Technology), tubulin (T6199, Sigma-Aldrich). Peroxidaseconjugated secondary antibodies were from GE HealthCare. HRP-conjugated Clean-blot IP Detection Reagent was used for immunoblotting immunoprecipitation experiments and was from Thermo Scientific. Secondary Alexa Fluor- conjugated secondary antibody was from Life Technologies.

\section{Cell culture}

Mouse primary keratinocytes (MPKs) were isolated and cultured as described (24), using complete EMEM: EMEM (Lonza) supplemented with 4\% FCS (Biowest) previously treated with Chelex 100, $100 \mathrm{U} / \mathrm{ml}$ penicillin $/ 100 \mu \mathrm{g} / \mathrm{ml}$ streptomycin (Biowest) and $2.5 \mu \mathrm{g} / \mathrm{mL}$ amphotericinB (Biowest). The skin of newborn (P0-P3) wild type mice was incubated in $0.25 \%$ trypsin at $4^{\circ} \mathrm{C}$ overnight. The epidermis was separated from the dermis, minced, and homogenized in complete EMEM with $0.05 \mathrm{mM} \mathrm{CaCl}_{2}$. Samples were pooled and the resulting suspension was filtered through a cell strainer (BD Biosciences). Cells were counted and plated on collagen I (Gibco)-coated culture dishes in complete EMEM with $0.6 \mathrm{mM} \mathrm{CaCl}$. The following day, cells were washed with DPBS (Biowest) and incubated in complete EMEM with $10 \mathrm{ng} / \mathrm{mL}$ EGF (Peprotech) and $0.05 \mathrm{mM} \mathrm{CaCl}_{2}$ until nearly confluent.

$\mathrm{GR}^{\mathrm{EKO}}$ and control keratinocyte cell lines were generated from 8-wk-old female mouse dorsal skin as previously described (18) and cultured on mitomycin C treated J2-3T3 feeders in collagen I-coated flasks in DMEM-Ham's F12 (3:1) medium (Gibco) supplemented with $1.8 \times$ $10^{-4} \mathrm{~mol} / \mathrm{L}$ adenine, $0.35 \mathrm{mM}$ calcium, $7.5 \% \mathrm{FCS}, 100 \mathrm{U} / \mathrm{ml}$ penicillin $/ 100 \mu \mathrm{g} / \mathrm{ml}$ streptomycin (Biowest), $2 \mathrm{mM}$ glutamine (Biowest), $0.25 \mu \mathrm{g} / \mathrm{mL}$ amphotericinB (Biowest), $5 \mu \mathrm{g} / \mathrm{ml}$ insulin, $10^{-10} \mathrm{M}$ cholera toxin and $10 \mathrm{ng} / \mathrm{ml}$ EGF (Peprotech). 
Prior to treatment with $100 \mathrm{nM}$ Dex, to deplete steroid hormones, cells were grown for 18-24 $\mathrm{h}$ in respective medium containing charcoal-stripped serum. To induce terminal differentiation, keratinocytes were incubated with medium containing $1.2 \mathrm{mM} \mathrm{CaCl}_{2}$.

\section{Chromatin Immunoprecipitation and ChIP-seq}

ChIP experiments were performed as previously described (24), using MPKs or adult keratinocyte cell lines grown to confluency in $100 \mathrm{~mm}$ culture dishes (Thermo Scientific). Keratinocytes were incubated with freshly prepared $1 \%$ formaldehyde 8 minutes at room temperature, lysed and sonicated using the Bioruptor (Diagenode) to fragment chromatin. Immunoprecipitation was done with $3 \mu \mathrm{g}$ of the indicated antibodies and Dynabeads Protein A (Life Technologies). After ChIP, reversion of cross-linking, and treatment with proteinase $\mathrm{K}$ and RNase, DNA was purified by phenol-chloroform extraction. Glycogen (Roche) was added to visualize pellet. QPCR (see below) was performed to assess the relative amplification of specified genomic sites in Dex vs mock-treated ChIPs, which were normalized to the amplification values of respective inputs. At least three biological replicates were used for each experimental group and technical triplicates were assessed to calculate the mean value $\pm \mathrm{SD}$. Statistical significance was calculated using the Student's t test.

GR ChIP-seq was performed as indicated by the manufacturer (Illumina-Solexa, http://www.illumina.com) (25). The quality of Input and ChIP DNA was first verified by Bioanalyzer (Agilent). Then, for library generation, oligonucleotide adapters were added to the DNA fragments which were then subjected to amplification and size selection. The resulting DNA quality was tested by QPCR at identical genomic regions as the original DNA. Next, DNA was sequenced by the Genome Analyzer II (Illumina) and data files processed using two different sequence alignment tools (Novoalign and MAQ) along with three different peak callers (SISSR, PeakRangers and MACS). The 123 selected peaks are those which had overlap between all algorithms and therefore are of high confidence (Table S1).

Peaks were assigned to genes using GREAT software. Gene ontology of genes with assigned peaks was carried out using DAVID (http://david.abcc.ncifcrf.gov/). Search of the 
transcription factor binding motifs in identified GR-bound regions was done using MEME (http://meme.nbcr.net/meme/).

\section{RNA isolation and Quantitative RT-PCR}

Total RNA was isolated from cultured keratinocytes using Trizol (Life Technologies). RNA was treated with DNase (Thermo Scientific), for later use with primer pairs which bind within the same exon, and reverse transcribed using RevertAid H Minus Reverse Transcriptase and oligo dT primers (Thermo Scientific). QPCR using specific oligonucleotides (Table S2) and FastStart Universal SYBR Green Master ROX (Roche) was carried out in an Applied Biosystems 7500 Fast real time PCR system. At least three biological replicates were used for each experimental group and technical triplicates were assessed to calculate the mean value \pm SD. Statistical significance was calculated using the Student's t test.

\section{Klf4 knockdown}

Keratinocytes were transfected with 25 nM Klf4 specific (L04001010005) or Control (D0018101005) On-Target plus siRNA Smartpool (Thermo Scientific) using Lipofectamine 2000 (Life Technologies) and Optimem medium (Life Technologies). Transfection was carried out in DMEM-Ham's 12 medium without antibiotics or antimycotic. Medium was changed 5 hours after addition of siRNA-Lipofectamine 2000 complexes. Experiments were conducted 48 hours following transfection.

\section{Immunoblotting}

Keratinocytes were lysed in RIPA buffer $(50 \mathrm{mM}$ Tris $\mathrm{HCl} \mathrm{pH} 8,150 \mathrm{mM} \mathrm{NaCl}, 1 \% \mathrm{NP}-40$, $0.5 \%$ sodium deoxycholate, $0.1 \%$ SDS) and samples were boiled in Laemmli buffer and separated on $8 \%$ SDS-PAGE $(25 \mu \mathrm{g} / \mathrm{lane})$, then transferred to nitrocellulose membranes (Hybond ECL, GE Healthcare). Membranes were stained with Ponceau S to verify equal protein loading and transfer. Membranes were blocked with 5\% nonfat dry milk in PBS- $0.1 \%$ Tween 20, and incubated with primary antibodies overnight at $4^{\circ} \mathrm{C}$. After washing three times 
in PBS- $0.1 \%$ Tween 20, membranes were incubated with peroxidase-conjugated secondary antibodies, washed again, and analyzed using ECL2 (Thermo Scientific) with the ImageQuant 4000 Biomolecular Imager (GE Healthcare). Experiments were quantitated using Image J software and were performed with a minimum of at least three biological replicates.

\section{Immunoprecipitation}

Keratinocytes were lysed in buffer containing $50 \mathrm{mM}$ Tris $\mathrm{pH} 7.6,150 \mathrm{mM} \mathrm{NaCl}, 5 \mathrm{mM}$ EDTA, 0.5\% Igepal CA-630 with protease and phosphatase inhibitors (Roche). Proteins were immunoprecipitated using $2 \mu \mathrm{g}$ of Klf4 specific antibody or rabbit IgG as a negative control and Dynabeads Protein A (Life Technologies). Following washing with buffer containing $0.2 \%$ Igepal CA-630, proteins were eluted from beads by boiling in Laemmli buffer for analysis by immunoblotting. 


\section{Results and Discussion}

To understand how GR transcriptionally regulates keratinocyte homeostasis and differentiation, we performed ChIP-sequencing (ChIP-seq) analysis in mouse primary keratinocytes (MPKs) that were treated either with vehicle or Dex for $2 \mathrm{~h}$. Following peak calling, we identified GR bound to 123 regulatory sequences upon Dex treatment (Table S1).

Our data identified a limited number of GBSs relative to other ChIP-seq approaches that reported GBSs were within the range of thousands (26-28), however, subsequent validation confirmed the accuracy of the data (see below). The identified GR ChIP-seq peaks corresponded to both known and novel GR-target genes in keratinocytes. The anti-inflammatory genes Tscd22d3/Gilz and Zfp36, the circadian rhythm gene Per1, and the receptor tyrosine kinase-like orphan receptor Ror1, among others, have been previously reported as GR-targets in other cell types (29). In keratinocytes, these genes are known to be regulated by Dex, though the precise binding sites of GR and the mechanism of regulation in this cell type were unknown (30). Importantly, the relatively small number of GBSs identified in our ChIP-seq is in agreement with the finding that few genes were detected as having changes in expression in human keratinocytes treated with Dex for 1 or $4 \mathrm{~h}$, as compared to later time-points where the expression of hundreds of genes was altered (30).

We first confirmed the regulation of identified genes by hormone-activated GR in an independent experiment in MPKs. ChIP of Dex or mock-treated (2h) cells using an anti-GR antibody followed by quantitative (Q)-PCR demonstrated direct, ligand dependent recruitment of GR to putative regulatory sequences of Per1, Tscd22d3 and Zfp36 (Fig. 1A). Differences were statistically significant, as assessed by Student's t test. Consistently, Tscd22d3 and Per1 expression was induced by 6 -fold or more and Zfp36 by almost 2 -fold after hormone treatment (Fig. 1B). These results validated our ChIP-Seq data and confirmed that the identified high confidence peaks were "true" GR primary targets.

To overcome the inherent difficulties in working with primary keratinocytes (17), we established spontaneously immortalized adult keratinocyte cell lines (20). There are differences in the basic biology of keratinocytes depending on the developmental stage and whether they 
are primary or immortal (31). Therefore, we evaluated whether Dex treatment induced similar GR recruitment and gene expression changes in our control adult cell line (CO) relative to primary newborn keratinocytes. We focused on Tsc22d3 and Zfp36 because they are known anti-inflammatory genes whose regulation and function in the epidermis are not well understood. Indeed, both GR recruitment (Fig. 1C) and gene induction of Tscd22d3 and Zfp36 (Fig. 1D, CO) occurred to a similar extent in the adult keratinocyte cell line as observed in newborn primary cells (Fig. 1A,B), indicating that in the case of these genes developmental stage (or primary or immortal status) does not affect regulation by GCs. We used a GR deficient cell line derived from adult $\mathrm{GR}^{\mathrm{EKO}}$ epidermis to unequivocally determine the dependence of Dex-induced changes in gene expression on this TF (Fig. 1E; 20). In $\mathrm{GR}^{\mathrm{EKO}}$ cells, neither Tsc22d3 nor Zfp36 were induced by Dex, showing that the presence of GR is necessary for this process (Fig. 1D, GR ${ }^{\mathrm{EKO}}$ ).

We searched the identified GR ChIP-seq peaks for the presence of consensus GRE (AGAACAnnnTGTTCT) using MEME (http://meme.nbcr.net/meme/) and found GRE motifs in $64 \%$ of putative regulatory regions (Table S1). Considering that GR binds to composite elements, we searched for co-occurrence of binding motifs of other TFs in the sequences of the GR bound peaks. In the 123 sequences analysed, several over-represented TF motifs, including KLF (43\%) and AP-1 (28\%) were identified (Table S1).

GR transrepression of AP-1 dependent transcription is well known, especially in the regulation of genes associated with inflammation (29). However, AP-1 can also facilitate the accessibility of GR to genomic binding sites by maintaining the chromatin in a more accessible conformation (32). In contrast, there are fewer examples for functional interactions between GR and KLFs, which occur in a tissue specific fashion, due to differing expression patterns of individual KLF members $(9,33)$. For instance, Klf11, in a neuronal cell line and Klf15 in a lung cell line were found to co-bind with GR to regulatory regions of target genes $(34,35)$. A very recent study in macrophages identified GR and KLF binding sites in genes encoding Klf2 and Klf9 and in the GR targets Cited and Mt2 (33). Our ChIP-Seq data also suggest that GR and KLFs co-regulate a KLF member, as putative sites for both TFs were identified in Klf13 (Table 
S1). Aside from these specific examples, the significance of the cooperation between KLFs and GR is still limited.

We next focused on Klf4 as a possible candidate for binding KLF motifs in the identified regions bound by GR given the known involvement of both TFs in epidermal development and homeostasis. Comparison of previous gene expression studies has shown an extensive overlap between genes regulated by GR and Klf4, mostly related to epidermal differentiation $(17,18,24,36)$. Additionally, there is an overlap between direct GR targets identified here and Klf4 regulated genes in human keratinocytes (Table S1; 37).

GR-bound sequences near Tscd22d3 and Zfp36 contained consensus GREs as well as adjacent KLF motifs (Table S1 and Fig. 2A). We assessed Klf4 recruitment to putative Tsc22d3 and Zfp36 regulatory regions by ChIP-QPCR and found statistically significant increases in Klf4 binding to both (4.7-fold and 2.9-fold, respectively) upon Dex treatment of control cells (Fig. 2B). In GR-deficient keratinocytes, in the case of Tsc22d3, Dex-dependent recruitment of Klf4 was decreased by almost 3 -fold relative to that observed in control cells. The slight induction (1.7 fold) of Klf4 binding to Tsc22d3 in Dex-treated GR ${ }^{\mathrm{EKO}}$ cells, was not statistically significant but may reflect a role of the mineralocorticoid receptor, closely related to GR and able to bind GCs. Importantly, the binding of Klf4 to Zfp36 was greatly reduced both in the absence and presence of Dex ( 0.22 fold and 0.39 fold, respectively) in $\mathrm{GR}^{\mathrm{EKO}}$ relative to control cells (Fig. 2B). The Dex- and GR-dependent recruitment of Klf4 to both genomic regions suggests cooperation between both TFs in regulating these anti-inflammatory genes. Given that several KLFs promote the anti-inflammatory program in macrophages, functional cooperation between GR and this family of TFs was postulated as a mechanism to counteract inflammation in these cells (33).

To further analyze the contribution of Klf4 to the regulation of Tsc22d3 and Zfp36, we transfected the control cell line with siRNA specific for Klf4 and achieved approximately $60 \%$ knockdown (Fig. 3). Dex-induction of Tsc22d3 was decreased by approximately 2-fold in cells expressing the KIf4 siRNA relative to control siRNA. Our results demonstrate that not only GR but also Klf4 is required for induction of $T s c 22 d 3$ in the presence of Dex. While Klf4 was 
required for Tsc22d3 induction, decreased Klf4 levels did not affect that of Zfp36. This may be due to incomplete knockdown or to a different role of Klf4 in the regulation of this gene.

There is controversy regarding whether GCs regulate Klf4 gene expression in epidermal keratinocytes. While Klf4 mRNA was not up-regulated by antenatal GC treatments in developing mouse skin (17), it was induced by Dex treatment of cultured human keratinocytes (30). We assessed Klf4 basal gene expression in adult cell lines and found decreased mRNA levels in $\mathrm{GR}^{\mathrm{EKO}}$ vs control cells (Fig. S1); however, no Klf4 induction was found in control keratinocytes treated with Dex for 3 to $24 \mathrm{~h}$ (Fig. 3 and data not shown). In contrast, in other cell types such as macrophages, Klf4 is induced by Dex treatment possibly through GR recruitment to two putative GREs located at -3830 bp and +5896 bp relative to the Klf4 transcription start site (33). These differences may be due to cell-type specific expression of co-regulators.

We also evaluated whether GR and Klf4 associated upon treatment with Dex (Fig. S2). While a small amount of GR was detected in Klf4 immunoprecipitates in the absence of hormone, it did not increase upon Dex treatment, indicating a mechanism other than direct protein-protein interaction for GC-induced recruitment of Klf4 (Fig. S2). We speculate that the mechanism of Klf4 recruitment could be similar to the Dex-induced de novo remodeling of chromatin near GR binding sites (enriched for canonical GREs) and assisted loading of the TF $\mathrm{C} / \mathrm{EBP} \beta$ observed in liver (28).

It is well known that treatment of cultured keratinocytes with high calcium concentrations $(1.2 \mathrm{mM})$ induces cell differentiation. Consistent with its role in terminal differentiation, Klf4 is induced in human primary keratinocytes grown in high calcium medium for $72 \mathrm{~h}$ (37). GR protein has also recently been described to be up-regulated in keratinocytes cultured in high calcium conditions (38). To evaluate whether Klf4 induction can compensate for the loss of GR in keratinocytes, confluent control and $\mathrm{GR}^{\mathrm{EKO}}$ cells were grown in high calcium (1.2 mM) containing medium for 0 or $72 \mathrm{~h}$ (Fig. 4). Control keratinocytes underwent terminal differentiation in the presence of high calcium, featuring cell flattening, extensive cellcell contacts, stratification and formation of cornified envelopes (Fig. 4A; asterisks). The expression of the differentiation marker Sprr2d was strongly induced in calcium-treated control 
cells, as shown by RT-QPCR (Fig. 4B). In contrast, GR ${ }^{\mathrm{EKO}}$ cells showed an aberrant morphology featuring spindle-like phenotype with decreased cell-cell contacts even in low calcium conditions (Fig. 4A). In high calcium medium, $\mathrm{GR}^{\mathrm{EKO}}$ cells failed to properly differentiate, as seen by the lack of cornified envelopes (Fig. 4A) which was further confirmed by the lack of Sprr2d induction (Fig. 4B).

Importantly, neither Klf4 mRNA nor protein was induced in calcium treated $\mathrm{GR}^{\mathrm{EKO}}$ cells, whereas both were induced in the control (Figs. 4B and 5C,D). We did not observe Nr3c1 up-regulation in terminally differentiated control cells; however GR protein levels did show a modest increase in agreement with Yoon et al. ((38); Figs. 4B and 5C,D). Notably, we observed an increase of Tsc22d3 and Zfp36 expression in differentiating control cells (Fig. 4B). In contrast, in $\mathrm{GR}^{\mathrm{EKO}}$ cells, calcium treatment did not result in up-regulation of $Z f p 36$; and Tsc22d3 showed a 3 -fold decrease in induction relative to the control (Fig. 4B). We postulate that the decreased induction of these genes, in addition to that of Klf4, in $\mathrm{GR}^{\mathrm{EKO}}$ cells may interfere with keratinocyte differentiation. For instance, the negative signaling of TSC22D3 on the RAS/RAF/ERK pathway $(1,2)$ could be important in halting proliferation during differentiation. While ZFP36 is best known for destabilization of Tnf and Csf2, currently there are more than 40 known targets including a wide range of cytokines, which can affect keratinocytes, and factors involved in cell cycle control such as Cyclin D1 (39).

As Klf4 expression was not affected by short treatments with Dex (Fig. 3), we considered other mechanisms for its misregulation in $\mathrm{GR}^{\mathrm{EKO}}$ cells. We previously observed that $\Delta \mathrm{Np} 63$ expression, the predominant isoform of Trp63 in epidermis (40), was reduced in oral epithelia of K5-GR transgenic mice, suggesting negative regulation by GR (41). Importantly, $\Delta$ Np63 represses Klf4 expression by directly binding its promoter (42), and the expression of both TFs is mutually exclusive in the epidermis, with $\Delta \mathrm{Np} 63$ expressed basally and Klf4 suprabasally. We evaluated whether GR could regulate Klf4 indirectly by modulating p63 expression, first by testing whether p63 isoform levels were affected by Dex in control and $\mathrm{GR}^{\mathrm{EKO}}$ cell lines (Fig. $5 \mathrm{~A}$ ). The levels of both $\Delta \mathrm{Np} 63$ and TAp63 were diminished by Dex in 
control keratinocytes while no effect was observed in $\mathrm{GR}^{\mathrm{EKO}}$ cells (Fig. 5A). These data show that activated GR is capable of repressing the expression of Trp63 isoforms. Strikingly, TAp63 levels were elevated by 2 -fold in $\mathrm{GR}^{\mathrm{EKO}}$ relative to control cells (Fig. 5A). While TAp63 has tumor suppressor properties (43), inducible epidermal overexpression causes hyperproliferation and a failure to commit to terminal differentiation (44), indicating functions dependent on cellular context and on the ratio to the $\Delta \mathrm{Np} 63$ isoform.

We next examined the expression of p63 isoforms in control and $\mathrm{GR}^{\mathrm{EKO}}$ keratinocytes grown in high calcium medium for $72 \mathrm{~h}$ (Fig. 5B). Here, we observed an increased expression of both $\Delta$ Np63 (1.8-fold) and TAp63 (6.6-fold) isoforms in $\mathrm{GR}^{\mathrm{EKO}}$ cells prior to incubation with calcium. As the calcium experiments are done in the presence of complete serum and the Dex treatments with charcoal-stripped serum, it is likely that other lipophilic compounds may participate in the basal regulation of $\Delta \mathrm{Np} 63$. In the presence of calcium, $\Delta \mathrm{Np} 63$ was upregulated in $\mathrm{GR}^{\mathrm{EKO}}$ keratinocytes, while TAp63 expression was not affected (Fig. 5B). Importantly, immunoblotting experiments confirmed the results of the RT-QPCR experiments (Fig. 5C, D). Since Zfp36 is a p63-target gene (45), it is feasible that the reduced Zfp36 mRNA levels detected in $\mathrm{GR}^{\mathrm{EKO}}$ cells upon high calcium are not only due to the lack of GR but also to the augmented $\mathrm{p} 63$.

A major aim in the field is to understand how individual or combined TFs modulate transcriptional programs in epidermal development and disease. Until now, two genome wide chromatin binding studies have been done for Klf4 in keratinocytes but none for GR $(12,46)$. This study provides the first direct evidence that GR and Klf4 bind at genomic regulatory regions near the anti-inflammatory genes $T s c 22 d 3$ and Zfp36. Our observation that these genes were up-regulated during keratinocyte terminal differentiation in a GR-dependent manner is suggestive of roles beyond modulating inflammation. GC treatment is a standard therapy for countering skin inflammation, with GR activation suppressing inflammatory pathways in both keratinocytes and skin immune cells (4). In immune cells, Klf4 can mediate inflammatory signaling (47-49), however, whether it does so in keratinocytes was unknown. Taken together, 
our data shows direct cooperation between Klf4 and GR in keratinocyte gene regulation and uncovers a role for Klf4 in regulating anti-inflammatory genes in these cells.

\section{Acknowledgements}

This work was supported by grant SAF2011-28115 of the Ministerio de Economía y

Competitividad from the Spanish government. 


\section{References}

1. Vandevyver S, Dejager L, Libert C. Comprehensive overview of the structure and regulation of the glucocorticoid receptor. Endocr Rev 2014; 35: 671-693.

2. Kadmiel M, Cidlowski JA. Glucocorticoid receptor signaling in health and disease. Trends Pharmacol Sci 2013; 34: 518-530.

3. Surjit M, Ganti KP, Mukherji A, Ye T, Hua G, Metzger D, Li M, Chambon P. Widespread negative response elements mediate direct repression by agonist-liganded glucocorticoid receptor. Cell 2011; 145: 224-241.

4. Pérez P. Glucocorticoid receptors, epidermal homeostasis and hair follicle differentiation. Dermato-Endocrinology 2011; 3: 1-9.

5. So AY, Chaivorapol C, Bolton EC, Li H, Yamamoto KR. Determinants of cell- and gene-specific transcriptional regulation by the glucocorticoid receptor. PLoS Genet 2007; 3: e94.

6. John S, Sabo PJ, Thurman RE, Sung MH, Biddie SC, Johnson TA, Hager GL, Stamatoyannopoulos JA. Chromatin accessibility pre-determines glucocorticoid receptor binding patterns. Nat Genet 2011; 43: 264-268.

7. Zaret KS, Carroll JS Pioneer transcription factors: establishing competence for gene expression. Genes Dev 2011; 25: 2227-2241.

8. Voss TC, Schiltz RL, Sung MH, Yen PM, Stamatoyannopoulos JA, Biddie SC, Johnson TA, Miranda TB, John S, Hager GL. Dynamic exchange at regulatory elements during chromatin remodeling underlies assisted loading mechanism. Cell 2011; 146: 544-554.

9. Knoedler JR, Denver RJ. Krüppel-like factors are effectors of nuclear receptor signaling. Gen Comp Endocrinol 2014; 203: 49-59.

10. Sur I. Krüppel-like factors 4 and 5: unity in diversity. Curr Genomics 2009; 10: 594 603.

11. Takahashi K, Yamanaka S. Induction of pluripotent stem cells from mouse embryonic and adult fibroblast cultures by defined factors. Cell 2006; 126: 663-676.

12. Boxer LD, Barajas B, Tao S, Zhang J, Khavari PA. ZNF750 interacts with KLF4 and RCOR1, KDM1A, and CTBP1/2 chromatin regulators to repress epidermal progenitor genes and induce differentiation genes. Genes Dev 2014; 28: 2013-2026.

13. Segre JA, Bauer C, Fuchs E. Klf4 is a transcription factor required for establishing the barrier function of the skin. Nat Genet 1999; 22:356-360.

14. Bayo P, Sanchis A, Bravo A, Cascallana JL, Buder K, Tuckermann J, Schütz G, Pérez $\mathrm{P}$. Glucocorticoid receptor is required for skin barrier competence. Endocrinology 2006; 149: 1377-1388.

15. Aszterbaum M, Feingold KR, Menon GK, Williams ML. Glucocorticoids accelerate fetal maturation of the epidermal permeability barrier in the rat. J Clin Invest 1993; 91:2703-2708.

16. Jaubert J, Cheng J, Segre JA. Ectopic expression of kruppel like factor 4 (Klf4) accelerates formation of the epidermal permeability barrier. Development 2003; 130: 2767-2777.

17. Patel S, Xi ZF, Seo EY, McGaughey D, Segre JA. Klf4 and corticosteroids activate an overlapping set of transcriptional targets to accelerate in utero epidermal barrier acquisition. Proc Natl Acad Sci U S 2006; 103: 18668-18673.

18. Sevilla LM, Latorre V, Sanchis A, Pérez $P$ Epidermal inactivation of the glucocorticoid receptor triggers skin barrier defects and cutaneous inflammation. J Invest Dermatol 2013; 33: 361-370.

19. Budunova IV, Kowalczyk D, Pérez P, Yao YJ, Jorcano JL, Slaga TJ. Glucocorticoid receptor functions as a potent suppressor of mouse skin carcinogenesis. Oncogene 2003; 22: $3279-3287$. 
20. Latorre V, Sevilla LM, Sanchis A, and Pérez P. Selective ablation of glucocorticoid receptor in mouse keratinocytes increases susceptibility to skin tumorigenesis. J Invest Dermatol 2013; 33: 2771-2779.

21. Li J, Zheng H, Yu F, Yu T, Liu C, Huang S, Wang TC, Ai W. Deficiency of the Kruppel-like factor KLF4 correlates with increased cell proliferation and enhanced skin tumorigenesis. Carcinogenesis 2012; 33: 1239-1246.

22. Foster KW, Liu Z, Nail CD, Li X, Fitzgerald TJ, Bailey SK, Frost AR, Louro ID, Townes TM, Paterson AJ, Kudlow JE, Lobo-Ruppert SM, Ruppert JM. Induction of KLF4 in basal keratinocytes blocks the proliferation-differentiation switch and initiates squamous epithelial dysplasia. Oncogene 2005; 24: 1491-1500.

23. Rowland BD, Peeper DS. KLF4, p21 and context-dependent opposing forces in cancer. Nat Rev Cancer 2006; 6: 11-23.

24. Sevilla LM, Bayo P, Latorre V, Sanchis, Pérez P. Glucocorticoid receptor regulates overlapping and differential gene subsets in developing and adult skin. Mol Endocrinology 2010; 24: 2166-2178.

25. Massie CE, Mills IG. Mapping protein-DNA interactions using ChIP-sequencing. Methods Mol Biol 2012; 809:157-173.

26. Langlais D, Couture C, Balsalobre A, Drouin J. Regulatory network analyses reveal genome-wide potentiation of LIF signaling by glucocorticoids and define an innate cell defense response. PLoS Genet 2008; 4: e1000224.

27. John S, Sabo PJ, Thurman RE, Sung MH, Biddie SC, Johnson TA, Hager GL, Stamatoyannopoulos JA. Chromatin accessibility pre-determines glucocorticoid receptor binding patterns. Nat Genet 2011; 43: 264-268.

28. Grøntved L, John S, Baek S, Liu Y, Buckley JR, Vinson C, Aguilera G, Hager GL. C/EBP maintains chromatin accessibility in liver and facilitates glucocorticoid receptor recruitment to steroid response elements. EMBO J 2013; 32: 1568-1583.

29. Newton R Anti-inflammatory glucocorticoids: changing concepts. Eur J Pharmacol 2013; 724: 231-236.

30. Stojadinovic O, Lee B, Vouthounis C, Vukelic S, Pastar I, Blumenberg M, Brem H, Tomic-Canic M. Novel genomic effects of glucocorticoids in epidermal keratinocytes: inhibition of apoptosis, interferon-gamma pathway, and wound healing along with promotion of terminal differentiation. J Biol Chem 2007; 282: 4021-4034.

31. Yano S, Okochi $\mathrm{H}$. Long-term culture of adult murine epidermal keratinocytes. $\mathrm{Br} \mathrm{J}$ Dermatol 2005; 153(6): 1101-1104.

32. Biddie SC, John S, Sabo PJ, Thurman RE, Johnson TA, Schiltz RL, Miranda TB, Sung MH, Trump S, Lightman SL, Vinson C, Stamatoyannopoulos JA, Hager GL. Transcription factor AP1 potentiates chromatin accessibility and glucocorticoid receptor binding. Mol Cell 2011; 43: 145-155.

33. Chinenov Y, Coppo M, Gupte R, Sacta MA, Rogatsky I Glucocorticoid receptor coordinates transcription factor-dominated regulatory network in macrophages. BMC Genomics 2014; 15: 656

34. Grunewald M, Johnson S, Lu D, Wang Z, Lomberk G, Albert PR, Stockmeier CA, Meyer JH, Urrutia R, Miczek KA, Austin MC, Wang J, Paul IA, Woolverton WL,Seo S, Sittman DB, Ou XM. Mechanistic role for a novel glucocorticoid-KLF11 (TIEG2) protein pathway in stress-induced monoamine oxidase A expression. J Biol Chem 2012; 287:24195-24206.

35. Sasse SK, Mailloux CM, Barczak AJ, Wang Q, Altonsy MO, Jain MK, Haldar SM, Gerber AN. The glucocorticoid receptor and KLF15 regulate gene expression dynamics and integrate signals through feed-forward circuitry. Mol Cell Biol 2013; 33: 2104-2115.

36. Patel S, Kartasova T, Segre JA. Mouse Sprr locus: a tandem array of coordinately regulated genes. Mamm Genome 2003; 14: 140-148.

37. Sen GL, Boxer LD, Webster DE, Bussat RT, Qu K, Zarnegar BJ, Johnston D, Siprashvili Z, Khavari PA. ZNF750 is a p63 target gene that induces KLF4 to drive terminal epidermal differentiation. Dev Cell 2012; 22: 669-677. 
38. Yoon HK, Li ZJ, Choi DK, Sohn KC, Lim EH, Lee YH, Kim S, Im M, Lee Y, Seo YJ, Lee JH, Kim CD. Glucocorticoid receptor enhances involucrin expression of keratinocyte in a ligand-independent manner. Mol Cell Biochem 2014; 390: 289-295.

39. Brooks SA, Blackshear PJ. Tristetraprolin (TTP): interactions with mRNA and proteins, and current thoughts on mechanisms of action. Biochim Biophys Acta 2013; 1829: 666679.

40. Melino G. p63 is a suppressor of tumorigenesis and metastasis interacting with mutant p53. Cell Death Differ 2011; 18: 1487-1499.

41. Cascallana JL, Bravo A, Donet E, Leis H, Lara MF, Paramio JM, Jorcano JL, Pérez P. Ectoderm-targeted overexpression of the glucocorticoid receptor induces hypohidrotic ectodermal dysplasia. Endocrinology 2005; 146: 2629-2638.

42. Cordani N, Pozzi S, Martynova E, Fanoni D, Borrelli S, Alotto D, Castagnoli C, Berti E, Viganò MA, Mantovani R. Mutant p53 subverts p63 control over KLF4 expression in keratinocytes. Oncogene 2011; 30: 922-932.

43. Vanbokhoven H, Melino G, Candi E, Declercq W. p63, a story of mice and men. J Invest Dermatol 2011; 131: 1196-1120.

44. Koster MI, Lu SL, White LD, Wang XJ, Roop DR. Reactivation of developmentally expressed p63 isoforms predisposes to tumor development and progression. Cancer Res 2006; 66: 3981-3986.

45. Barton CE, Johnson KN, Mays DM, Boehnke K, Shyr Y, Boukamp P, Pietenpol JA Novel p63 target genes involved in paracrine signaling and keratinocyte differentiation. Cell Death Dis 2010; 1: e74.

46. Nascimento EM, Cox CL, MacArthur S, Hussain S, Trotter M, Blanco S, Suraj M, Nichols J, Kübler B, Benitah SA, Hendrich B, Odom DT, Frye M. The opposing transcriptional functions of $\operatorname{Sin} 3 \mathrm{a}$ and $\mathrm{c}-\mathrm{Myc}$ are required to maintain tissue homeostasis. Nat Cell Biol 2011; 13: 1395-1405.

47. Feinberg MW, Wara AK, Cao Z, Lebedeva MA, Rosenbauer F, Iwasaki H, Hirai H, Katz JP, Haspel RL, Gray S, Akashi K, Segre J, Kaestner KH, Tenen DG, Jain MK. The Kruppel-like factor KLF4 is a critical regulator of monocyte differentiation. EMBO J 2007; 26: 4138-4148.

48. Liao X, Sharma N, Kapadia F, Zhou G, Lu Y, Hong H, Paruchuri K, Mahabeleshwar GH, Dalmas E, Venteclef N, Flask CA, Kim J, Doreian BW, Lu KQ, Kaestner KH, Hamik A, Clément K, Jain MK. Krüppel-like factor 4 regulates macrophage polarization. J Clin Invest 2011; 121: 2736-2749.

49. Rosenzweig JM, Glenn JD, Calabresi PA, Whartenby KA. KLF4 modulates expression of IL-6 in dendritic cells via both promoter activation and epigenetic modification. J Biol Chem 2013; 288: 23868-23874. 


\section{Figure legends}

Figure 1. Tsc22d3 and Zfp36 are direct GR transcriptional targets in keratinocytes Experiments were performed in cultured mouse primary keratinocytes MPKs (A, B) or immortal adult keratinocyte cell lines (C, D).

A GR ChIP-QPCR demonstrates recruitment to putative regulatory sequences of Per1, Tsc22d3, and Zfp36 upon Dex treatment (100nM, 2h). Fold GR recruitment (mean values \pm SD) in Dex- vs mock- treated MPKs is shown, with asterisks denoting statistically significant differences between groups (Student's t-test, $\mathrm{n}=3 ;{ }^{*} \mathrm{p}<0.05, * * \mathrm{p}<0.01$ ).

B Dex treatment (100 nM, 3h) induces gene expression of Per1, Tsc22d3, and Zfp36 in MPKs as measured by RT-QPCR. Relative gene expression (mean values \pm SD) in Dex- versus mocktreated samples is shown, with asterisks denoting statistically significant differences between groups (Student's t-test; $\mathrm{n}=3 ; * * \mathrm{p}<0.01$ ).

C GR ChIP-QPCR demonstrates recruitment to putative regulatory sequences of Tsc22d3 and Zfp36 upon Dex treatment (100 nM, 2h) in control cell line. Fold GR recruitment (mean values $\pm \mathrm{SD}$ ) in Dex- vs mock- treated cells is shown, with asterisks denoting statistically significant differences between groups (Student's t-test, $\mathrm{n}=4 ;{ }^{*} \mathrm{p}<0.05,{ }^{* *} \mathrm{p}<0.01$ ).

$\mathrm{D}$ Gene expression of Tsc22d3 and Zfp36 in Dex- $(100 \mathrm{nM}, 3 \mathrm{~h})$ or mock-treated GR ${ }^{\mathrm{EKO}}$ and control (CO) cell lines was assessed by RT-QPCR. Relative gene expression (mean values \pm $\mathrm{SD}$ ) in Dex- versus mock-treated samples is shown, with asterisks denoting statistically significant differences between treatment groups (Student's t-test; $\mathrm{n}=3 ;{ }^{*}, \mathrm{p}<0.05 ;{ }^{* *}, \mathrm{p}<0.01$ ). $\mathrm{E}$ GR deficiency in the $\mathrm{GR}^{\mathrm{EKO}}$ relative to the control cell line (CO) is shown by immunoblotting. Tubulin was used as a loading control.

Figure 2. KIf4 is recruited to $T s c 22 d 3$ and Zfp36 in Dex-treated cells in a GR dependent manner.

A Genomic sequences near Tsc22d3 and Zfp36 to which ligand-bound GR was recruited in ChIP-seq. GREs and adjacent KLF and/or AP-1 sites are underlined.

B Klf4 recruitment to regions near Tsc22d3 and Zfp36 increases upon Dex treatment (100 nM, $2 \mathrm{~h}$ ) in control but not in $\mathrm{GR}^{\mathrm{EKO}}$ cells. Fold Klf4 recruitment (mean values $\pm \mathrm{SD}$ ) in Dex- relative to mock-treated $\mathrm{CO}$ and $\mathrm{GR}^{\mathrm{EKO}}$ cells is shown, with asterisks denoting statistically significant differences between treatment groups (Student's t-test; $\mathrm{n}=4{ }^{*}, \mathrm{p}<0.05 ;{ }^{* *}, \mathrm{p}<0.01$ ).

Figure 3. Knockdown of Klf4 interferes with Dex-induction of Tsc22d3 but not Zfp36.

$T s c 22 d 3$ and Zfp36 showed statistically significant increases in expression following treatment with Dex (100 nM, 3h) in cells transfected with control but not Klf4 siRNAs as shown by RTQPCR. Note the reduction of Klf4 levels in samples transfected with gene specific siRNA. Fold change (mean values $\pm \mathrm{SD}$ ) in expression relative to mock-treated control siRNA transfectants is shown, with asterisks denoting statistically significant differences between treatment groups (Student's $t$ test; $\mathrm{n}=4{ }^{*}, \mathrm{p}<0.05 ; * *, \mathrm{p}<0.01$ ).

Figure 4. Defective calcium-induced terminal differentiation in $\mathbf{G R}^{\mathrm{EKO}}$ cell line.

A Phase contrast images show morphological characteristics of calcium-induced differentiation in control $(\mathrm{CO})$ but not $\mathrm{GR}^{\mathrm{EKO}}$ cells after $72 \mathrm{~h}$ in the presence of $1.2 \mathrm{mM}$ calcium. Note the presence of cornified envelopes in control cells (asterisks) in contrast to striking defective differentiation of the $\mathrm{GR}^{\mathrm{EKO}}$ cells. Bar: $50 \mu \mathrm{m}$.

B Gene expression of Sprr2d, Nr3c1, Klf4, Tsc22d3, and Zfp36 in CO or GR ${ }^{\mathrm{EKO}}$ cells treated for 0 or $72 \mathrm{~h}$ with $1.2 \mathrm{mM}$ calcium was assessed by RT-QPCR. Changes in gene expression (mean values $\pm \mathrm{SD}$ ) relative to t0 are shown, with asterisks denoting statistically significant differences relative to untreated controls (Student's t-test; $\mathrm{n}=4 ; *, \mathrm{p}<0.05 ; * *, \mathrm{p}<0.01$ ). The graph has a logarithmic scale.

Figure 5. GR negatively regulates $\operatorname{Trp} 63$ isoforms in keratinocytes. 
A RT-QPCR shows that Dex-treatment (100nM, 3h) repressed expression of Trp63 isoforms $\triangle \mathrm{Np} 63$ and TAp63 in CO but not in $\mathrm{GR}^{\mathrm{EKO}}$ cells. Note the elevated levels of TAp63 in $\mathrm{GR}^{\mathrm{EKO}}$ relative to $\mathrm{CO}$ cells. Mean values $\pm \mathrm{SD}$ are shown, with asterisks denoting statistically significant differences relative to mock-treated (V) samples (Student's t-test; $\mathrm{n}=3 ; *, \mathrm{p}<0.05$; **, $\mathrm{p}<0.01)$.

B $\Delta$ Np63 and TAp63 isoforms show elevated expression during calcium-induced terminal differentiation in $\mathrm{GR}^{\mathrm{EKO}}$ versus $\mathrm{CO}$ cells as measured by RT-QPCR. Mean values $\pm \mathrm{SD}$ are shown, with asterisks denoting statistically significant differences in $\mathrm{GR}^{\mathrm{EKO}}$ relative to $\mathrm{CO}$ cells at each time-point (Student's t-test; $\mathrm{n}=3 ; *, \mathrm{p}<0.05 ; * *, \mathrm{p}<0.01$ ).

$\mathrm{C}$ Immunoblotting shows induction of GR and Klf4 protein during terminal differentiation in $\mathrm{CO}$ but not in $\mathrm{GR}^{\mathrm{EKO}}$ cells. Note the increase in $\mathrm{p} 63$ in $\mathrm{GR}^{\mathrm{EKO}}$ cell extracts. Tubulin was used as a loading control.

D. Quantification of immunoblotting experiments. Mean values \pm SD are shown, with asterisks denoting statistically significant differences between 0 and $72 \mathrm{~h}$ of calcium treatment within a genotype (Student's t-test; $\mathrm{n}=3 ; *, \mathrm{p}<0.05 ; * *, \mathrm{p}<0.01$ ), and hashes denoting statistically significant differences in $\mathrm{GR}^{\mathrm{EKO}}$ relative to $\mathrm{CO}$ cells at each time-point (Student's t-test; $\mathrm{n}=3$; \#, $\mathrm{p}<0.05 ; \#, \mathrm{p}<0.01)$. 
Figure 1
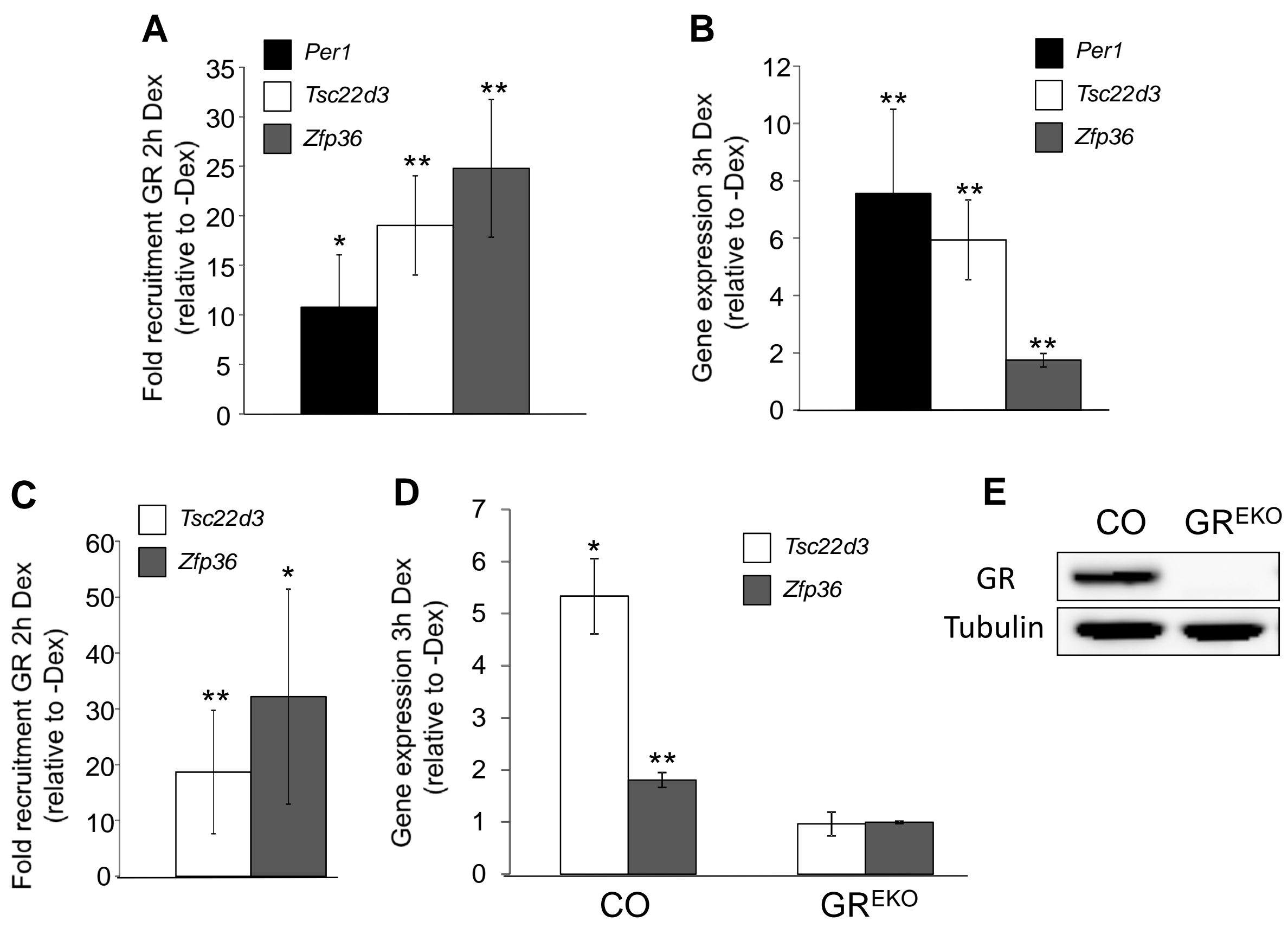
Figure 2

A

$\underline{\text { Tsc22d3, }}$ chrX:137063804-137064012

GGGCAAAAAACAGAATGTTCAGCATTCAAGGGAGGGGCAGGAGTTGGGTTCTGCCTGAGTAATTCTTG GRE

KLF

AP-1

Zfp36, chr7:29161362-29161638

TCCCGCACATTCCGTCCTCGCCGCCCCGCCCCACCCCGCCCTCCTTCCTTGGCCCTGTGGGGACGGAA GRE

KLF

ACATCCCGTTCCTGCCCGAGCTGGGTCAAGAGCCGGAGGGACAGGACCAGAGCACCCCTTAC

B

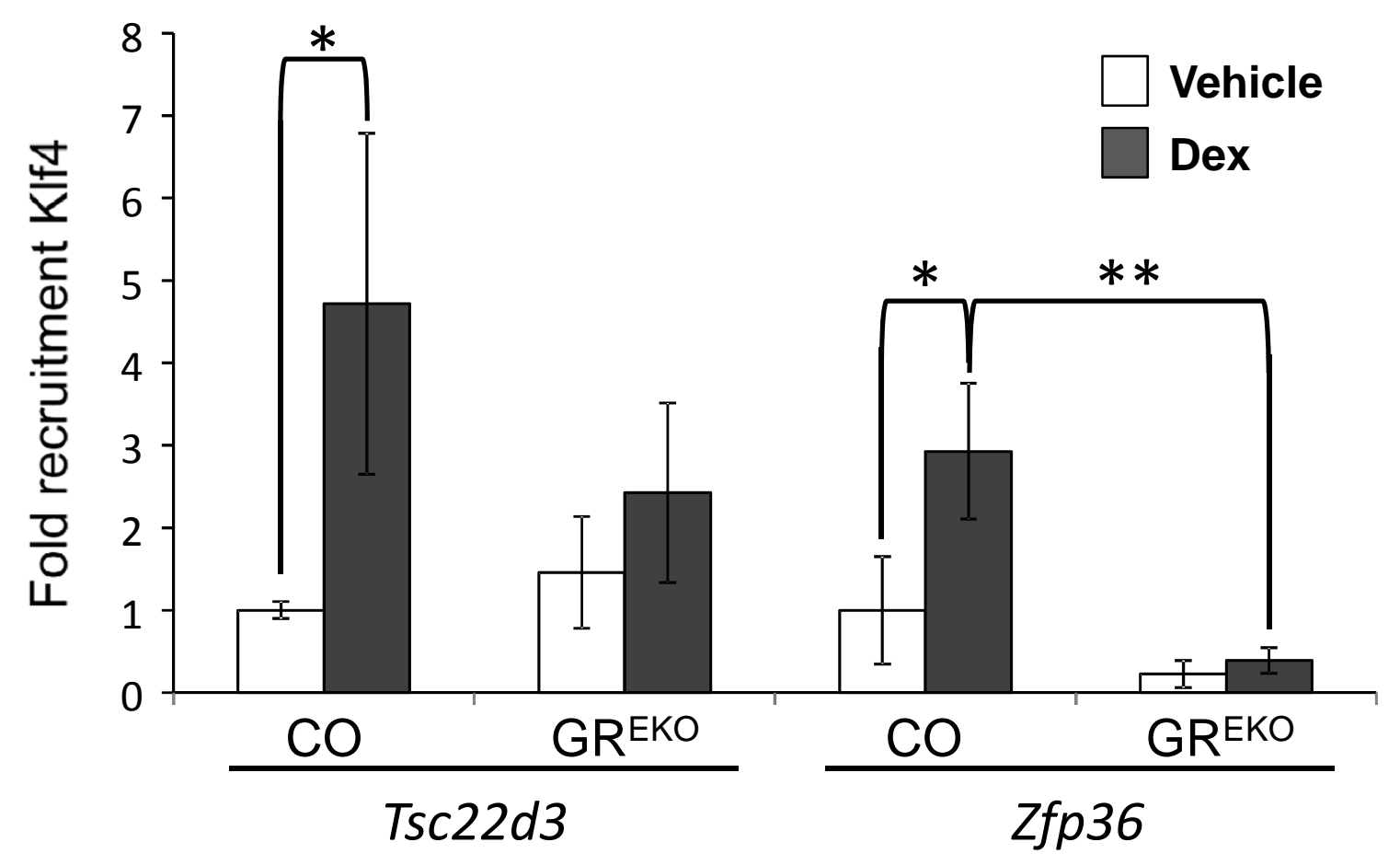

KLF 
Figure 3

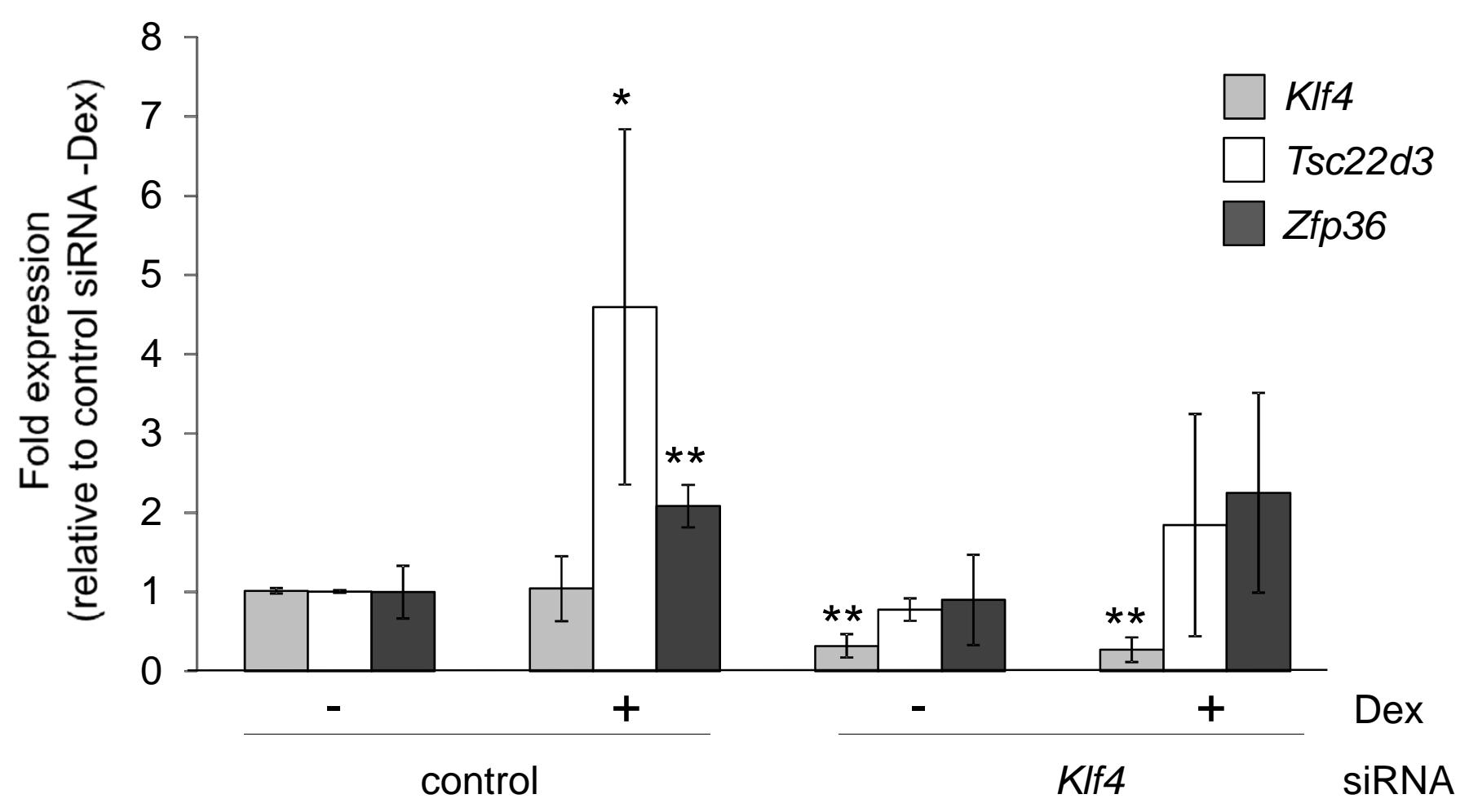


Figure 4

A

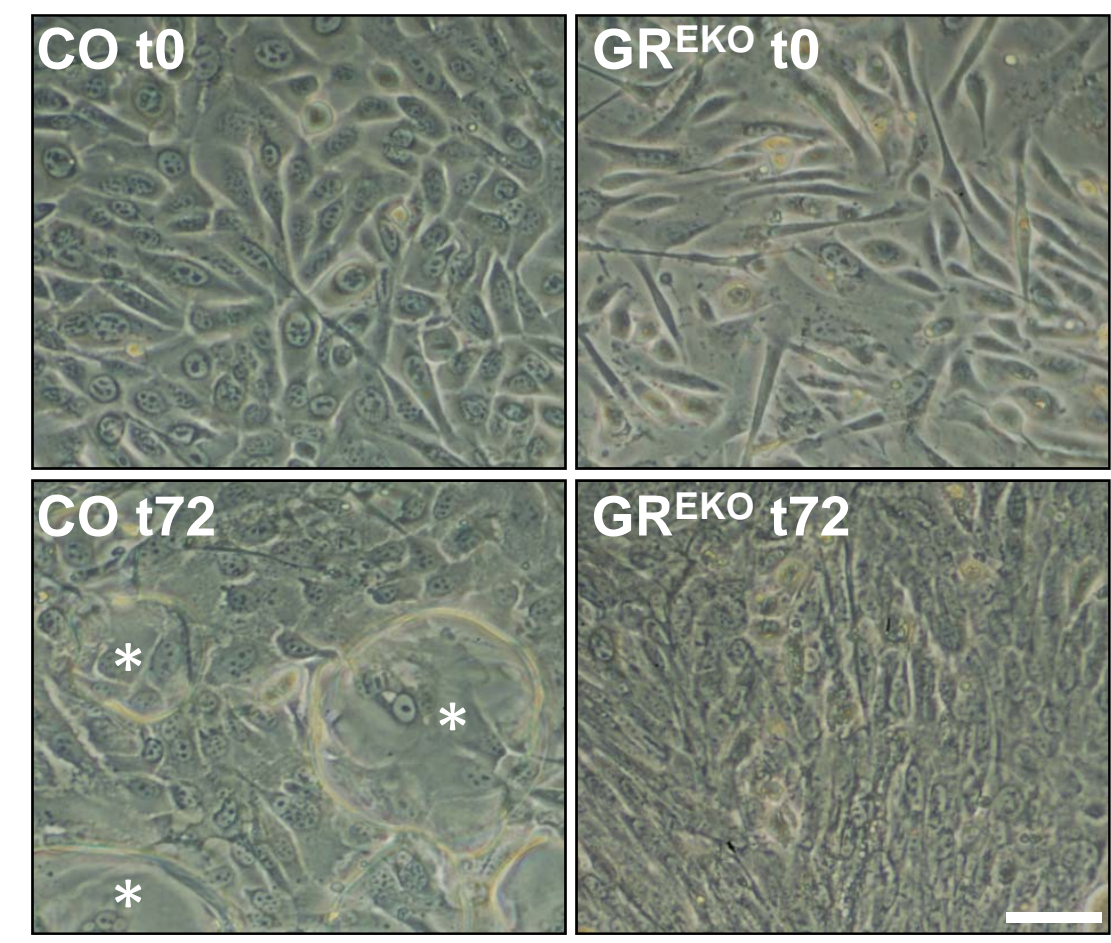

B

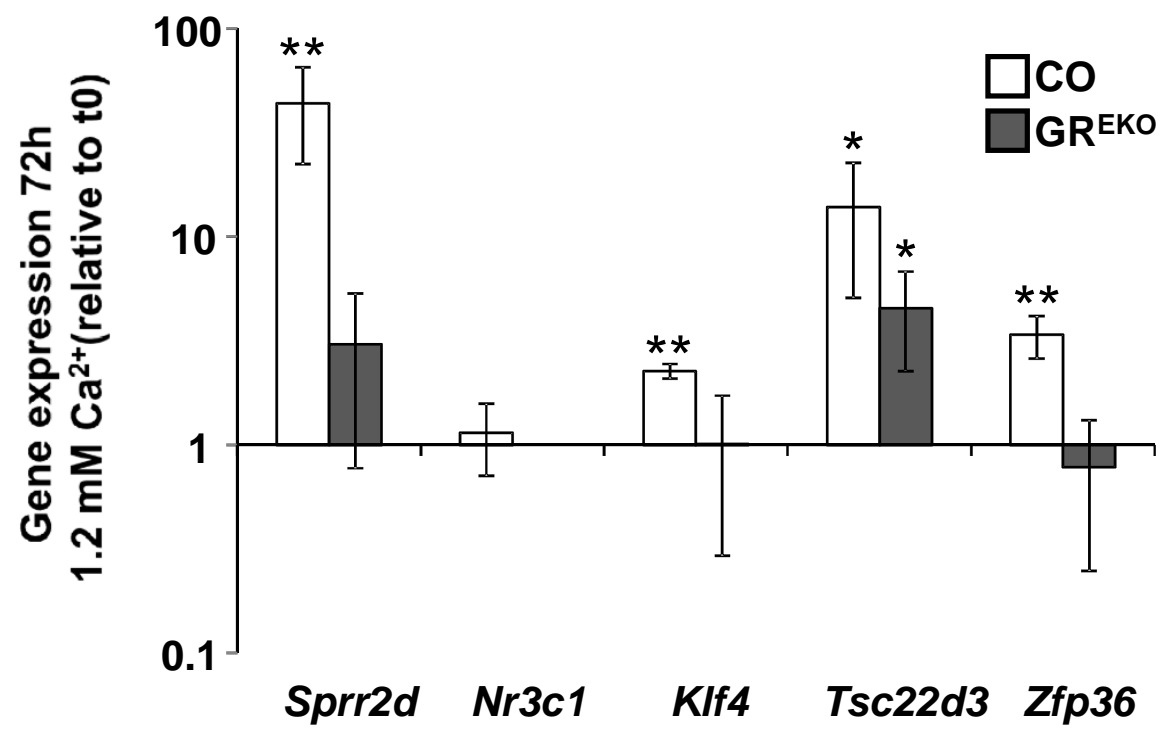


Figure 5

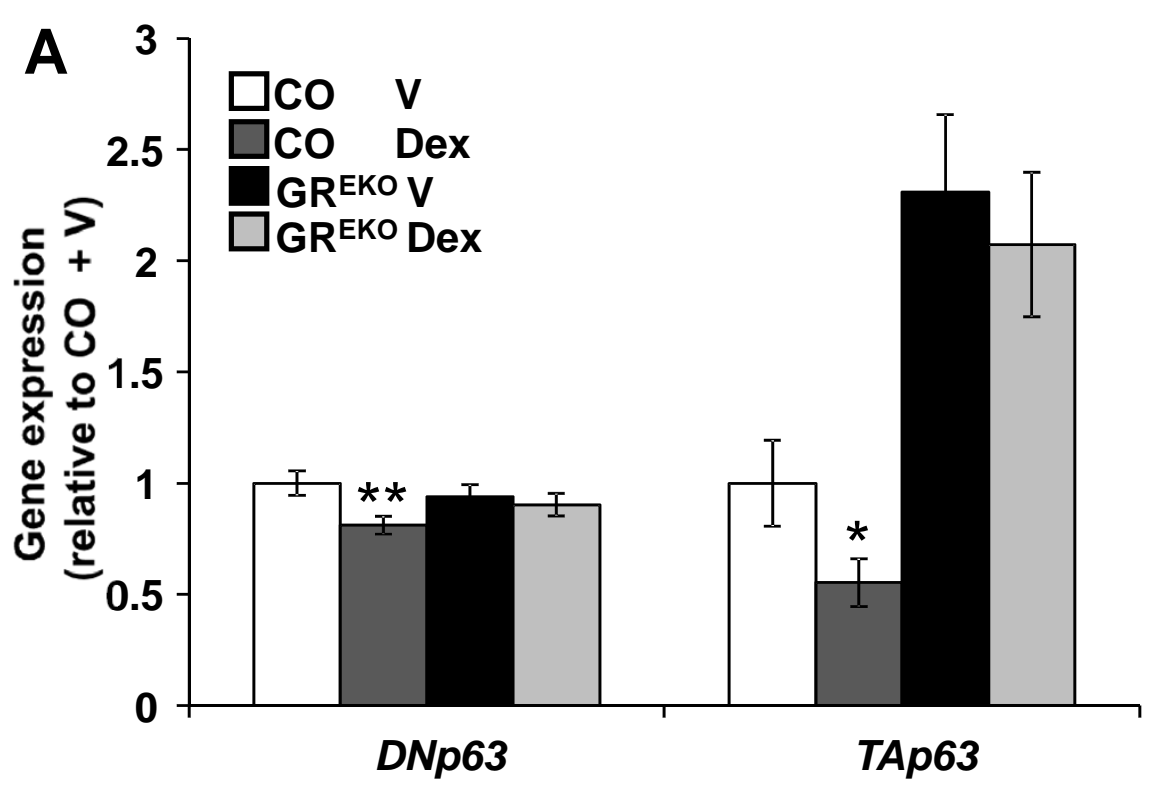

C

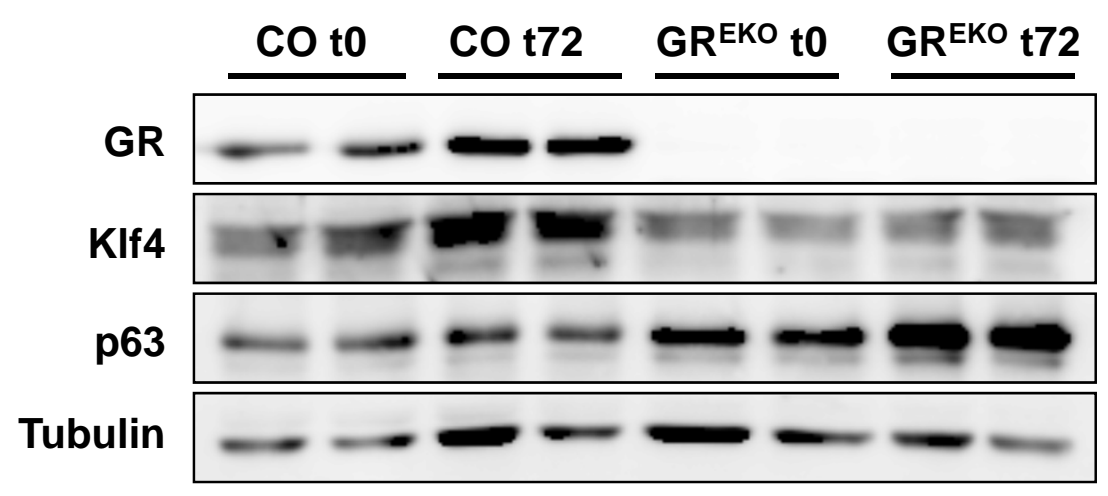

B
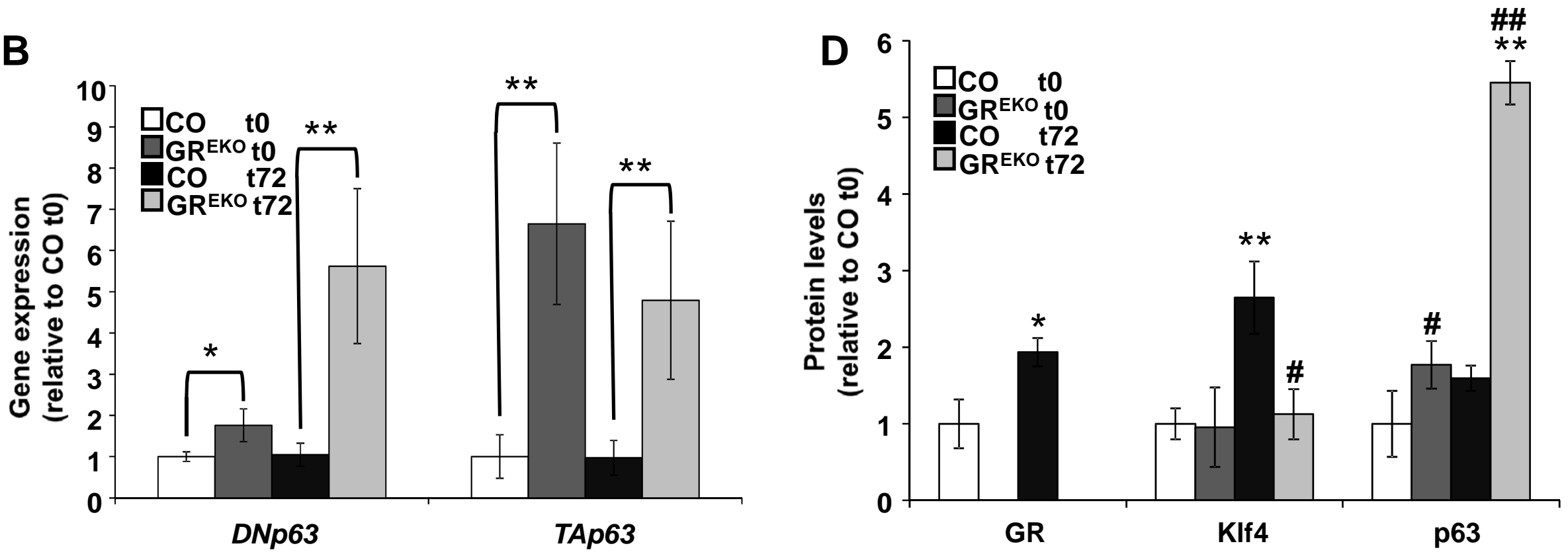


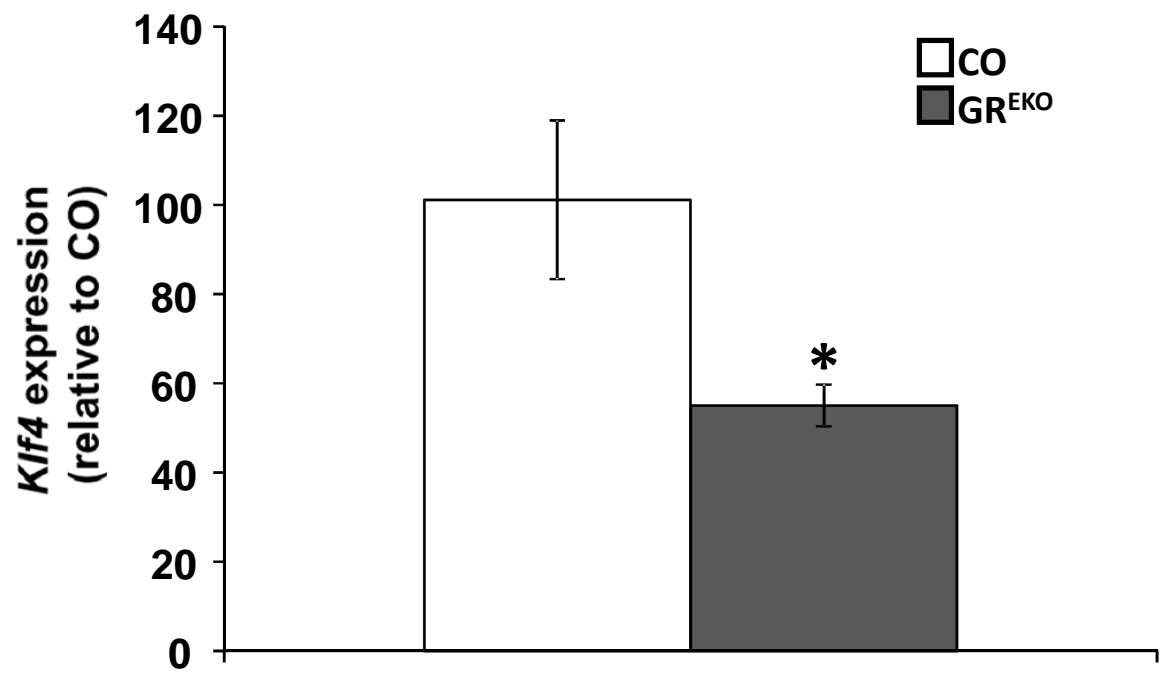

Figure S1- Reduced KIf4 expression in GR ${ }^{\mathrm{EKO}}$ versus $\mathrm{CO}$ cells.

Klf4 expression was assessed in GREKO versus CO cells by RT-QPCR.

Mean values \pm SD are shown, with asterisks denoting statistically significant differences in $\mathrm{GR}^{\mathrm{EKO}}$ relative to $\mathrm{CO}$ (Student's t-test; $\mathrm{n}=3$; * ${ }^{*} \mathrm{p}<0.05$ ). 


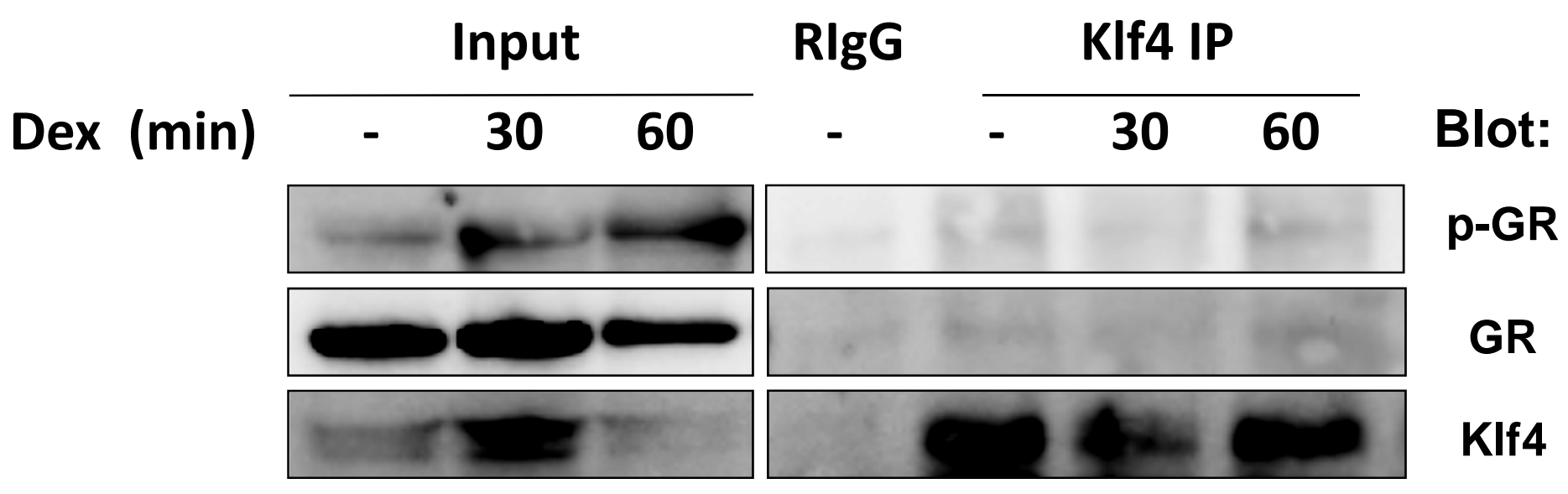

Figure S2- Evaluation of GR-KIf4 interaction via co-immunoprecipitation.

Lysates of cells treated with Dex for 0,30 or 60 min were subjected to immunoprecipitation with antibody specific for Klf4 or a nonspecific rabbit IgG (t0). Input controls and immunoprecipitates were analysed by immunoblotting with GR, p-GR and Klf4 antibodies. 


\begin{tabular}{|c|c|c|c|c|c|c|}
\hline Gene symbol & Chrom & Chrom_start & Chrom_end & pvalue $(-10 * \log 10) \quad$ GRE MOTIF & KLF MOTIF & AP1 MOTIF \\
\hline Per2 & chr1 & 93332598 & 93333431 & 227,42 GTGTACAGAATGTTCCTGGC & ACCCTCCCAACACA & \\
\hline Ralb & chr1 & 121405904 & 121406699 & 375,29 AGGGACAGAGAGTCCAGGAC & & CTGACTCA \\
\hline Nuak2 & chr1 & 134231906 & 134232468 & 335,65 GGCGGGATCATGATGTTCTT & & TGAGGCAC \\
\hline Gpr161 & chr1 & 167221433 & 167222346 & 521,77 & GGCCTGGGGCAGAG & \\
\hline AK017125 & chr1 & 174479598 & 174480468 & 408,64 AGGGACAGAGAGTTCCTCAC & TTCGACCACACCCC & \\
\hline Mthfd1l & chr10 & 6240400 & 6241159 & 375,8 ACACAGCACATAGTGTTCCT & AGTGTCTGGGAAGG & \\
\hline Moxd1 & chr10 & 24115658 & 24116564 & 437,16 TCAGAGGACAGTATGTACTG & & \\
\hline Anapc16 & chr10 & 59436557 & 59437575 & 968,69 AGCCAGAACACAATGTTCTC & TGAGAGGGGAGCAG & \\
\hline Unc5b & chr10 & 60267884 & 60268713 & 291,1 & & \\
\hline Lrrc20 & chr10 & 60927495 & 60928398 & 601,34 GCAGGGCACTCTGTGTACCC & TCGGGCCACACCCA & \\
\hline \multicolumn{7}{|c|}{ 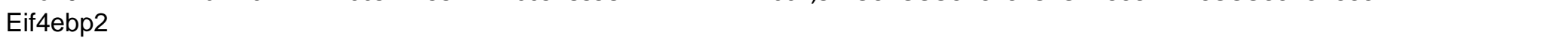 } \\
\hline Mknk2 & chr10 & 80126961 & 80127794 & 557,47 AGGAACAGCTCGTCCTAGGA & & \\
\hline Spred2 & chr11 & 19749542 & 19750339 & 338,36 & & \\
\hline Phf15 & chr11 & 51729371 & 51730267 & 1887,93 CAGGACACCCAGTCCTTGGC & ATGGGCCTCACACC & \\
\hline \multicolumn{7}{|c|}{ 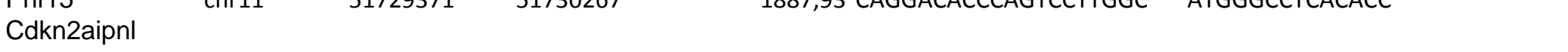 } \\
\hline Per1 & chr11 & 68910113 & 68911085 & 852,61 AGAACACGATGTTCC & CCCTGCCCCACATT & \\
\hline Krt42 & chr11 & 100148051 & 100148802 & 306,78 & CCGCACCCCACCCA & \\
\hline \multicolumn{7}{|c|}{ 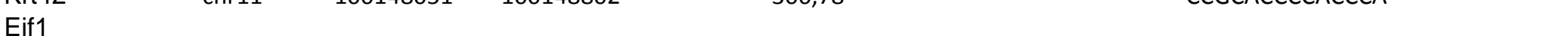 } \\
\hline \multirow{2}{*}{\multicolumn{7}{|c|}{ Rgs9 }} \\
\hline & & & & & & \\
\hline Sphk1 & chr11 & 116394671 & 116395715 & 334,06 & & \\
\hline Bahcc1 & chr11 & 120113752 & 120114488 & 432,05 & GGGGTGGGGCAGAA & \\
\hline Id2 & chr12 & 25854455 & 25855011 & 582,92 CCTGAGCACTCGGTGTTCCT & & GTGACTCA \\
\hline Tmx1 & chr12 & 71725183 & 71726107 & 265,87 & AGGGTGTGGCCAGG & \\
\hline \multicolumn{7}{|l|}{ Frmd6 } \\
\hline Fntb & chr12 & 77984680 & 77985374 & 540,5 AGGATCAGAATGTTCTGTAG & AGGGTGAGGCCCAG & \\
\hline Sel11 & chr12 & 93117244 & 93117946 & 537,46 ACGAACATTCTGTCCCAGAA & & ATGACTCA \\
\hline Rin3 & chr12 & 103566223 & 103566907 & 258,14 AAGTACATTGTGTCCTTTGA & AGGGTGGGGGTGGG & \\
\hline Klf6 & chr13 & 5840515 & 5841102 & 467,77 & АССТTCСАСТCCCT & \\
\hline Edn1 & chr13 & 42469301 & 42470237 & 833,31 AGCAGGGACACTGTGTTCCA & САСТTCCССTCCCT & \\
\hline Jarid2 & chr13 & 44964462 & 44965677 & 610,17 & & \\
\hline Gadd45g & chr13 & 52001157 & 52001951 & 346,71 & CCCAGCCCTACACT & \\
\hline AK014969 & chr13 & 52344718 & 52345676 & 595,48 ATGAACACGATGTTCCCTGA & & \\
\hline \multicolumn{7}{|l|}{ Diras2 } \\
\hline \multirow{2}{*}{\multicolumn{7}{|c|}{ 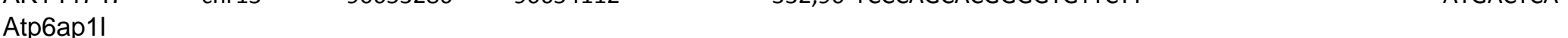 }} \\
\hline & & & & & & \\
\hline Hexb & chr13 & 97960232 & 97961100 & 581,96 TCTCAGGACCGACTGACCCA & & \\
\hline Grhl2 & chr15 & 37122163 & 37122985 & 699,67 GGGAACACTGTGTCCTTGTA & & ATGACTCA \\
\hline Azin1 & chr15 & 38386738 & 38387747 & 326,58 & & \\
\hline Eif3h & chr15 & 51561900 & 51562839 & 1048,8 & & \\
\hline AK163289 & chr15 & 61439440 & 61440444 & 315,03 & & \\
\hline Micall1 & chr15 & 78961713 & 78962462 & 364,9 AGTCACAGAATGTCCTTGGC & & GTGACTGA \\
\hline Krt6a & chr15 & 101527667 & 101528519 & 696,28 GCACTGCTCACTTTGTTCCC & & \\
\hline Zc3h7a & chr16 & 11143747 & 11144537 & 1228,4 & GGCGTCGGGACCGG & \\
\hline Parn & chr16 & 13506704 & 13507717 & 408,05 & ACTTGCCCCACCCA & \\
\hline Gnb1l & chr16 & 18547751 & 18548560 & 687,23 & & TGAGTCA \\
\hline AK053957 & chr16 & 25058959 & 25060033 & 545,38 & CCGGGCCCCTCCCA & \\
\hline Leprel1 & chr16 & 26248772 & 26249554 & 329,44 TAGAACATTGTATTCTTGGC & & TGAGTCAT \\
\hline \multicolumn{7}{|c|}{ (2) } \\
\hline AK029404 & chr16 & 31598510 & 31599566 & 427,38 AGGTACATCCAGTCCTGAGC & & \\
\hline \multirow{2}{*}{\multicolumn{7}{|c|}{ 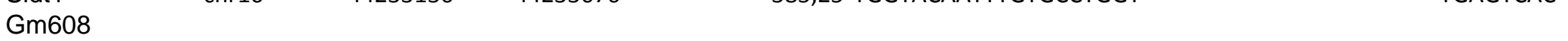 }} \\
\hline & & & & & & \\
\hline Cblb & chr16 & 52094514 & 52095248 & 326,83 AAGTACAGACTGTCCCAGGA & & TGAGTCTC \\
\hline Filip1l & chr16 & 57391129 & 57392285 & 2087,76 & & \\
\hline
\end{tabular}




\begin{tabular}{|c|c|c|c|c|c|c|}
\hline N6amt1 & chr16 & 87267971 & 87268910 & 902,63 GTCTGGCACTCACTCATCCA & TCCTGCCTGTCCCC & GTGACCCA \\
\hline BC099513 & chr16 & 95462765 & 95463864 & 659,75 TCACGGAACATATTGTACCT & & \\
\hline Ets2 & chr16 & 95880846 & 95881801 & 645,89 & & \\
\hline Hsf2bp & chr17 & 32048871 & 32049713 & 813,46 GGGAACATTCCGTCTCGGAA & & \\
\hline H2-T3 & chr17 & 36367717 & 36368869 & 1320,18 & сССТСТСССТСССС & \\
\hline \multicolumn{7}{|l|}{ AK138323 } \\
\hline Mir715 & chr17 & 39979485 & 39986313 & 3100 & & \\
\hline Mir715 & chr17 & 39979485 & 39986313 & 3100 & & \\
\hline Mir715 & chr17 & 39979485 & 39986313 & 3100 & & \\
\hline Mir715 & chr17 & 39979485 & 39986313 & 3100 & & \\
\hline Mir715 & chr17 & 39979485 & 39986313 & 3100 & & \\
\hline Tcf4 & chr18 & 68851589 & 68851983 & 633,78 & & \\
\hline \multicolumn{7}{|l|}{ Mc2r } \\
\hline AK009639 & chr19 & 5849726 & 5850617 & 1565,36 AGGTACATTCCGTTCCAGGC & TGGGCTGGGCCGGG & \\
\hline Hoga1 & chr19 & 42132697 & 42133507 & 527,69 GGCCATCACACCGTGTTCCT & & GTGACTCA \\
\hline Camk1d & chr2 & 5299883 & 5300572 & 692,92 & & \\
\hline 4921504E06Rik & chr2 & 19501239 & 19502198 & 240,9 AGACAGAATGCTCTGTTCAG & & GTGACTCA \\
\hline Pax8 & chr2 & 24295381 & 24296340 & 475,02 GGAGGGCACATGATGTACAA & & \\
\hline $\operatorname{ltgb6}$ & chr2 & 60537740 & 60538748 & 1361,25 CTGTACATTCTGTGCTGCTT & TGAGTGAGGAGAGG & \\
\hline Tсp11l1 & chr2 & 104545348 & 104546337 & 540,82 GGGAACAATTTGTGCTTTAG & & \\
\hline Bcl2/1 & chr2 & 152645660 & 152646435 & 420,7 TGAAGGGACACTGTGTTCCC & & \\
\hline Pxmp3 & chr3 & 5860456 & 5860990 & 2237,96 & & \\
\hline Zbtb7b & chr3 & 89182266 & 89183149 & 544,95 AGGAACAAGACATTCCCTGC & & TGAGTCA \\
\hline S100a10 & chr3 & 93359704 & 93360284 & 314,37 TAGCACAAAGGGTTCCTGGA & TGGGTGTGGCCTAG & GTGACTCA \\
\hline Wars2 & chr3 & 98953718 & 98954556 & 403,97 & & \\
\hline Pdlim5 & chr3 & 142035231 & 142036203 & 586,07 AGGAACAGAATGTCCCAGAC & & \\
\hline 4930503B20Rik & chr3 & 146320253 & 146321062 & 605,28 AGGTACACAATGTTCCAGCA & & ATGACTGA \\
\hline Ror1 & chr4 & 100073937 & 100075431 & 416,9 & & \\
\hline BC051525 & chr4 & 120289222 & 120289771 & 765,77 GGGAACACAGAGTCCTGGGC & GGGGTGGGGACCTG & \\
\hline Trnp1 & chr4 & 133047438 & 133048255 & 385,8 AGCAGGAATGGAATGTTCCT & СССТСССССАСССС & \\
\hline Clic4 & chr4 & 134842633 & 134843533 & 553,41 CCGCAGAACGCCCTGTACCG & CTCTGCCCTACCCA & \\
\hline \multicolumn{7}{|l|}{ Srrm1 } \\
\hline Kif17 & chr4 & 137834057 & 137834838 & 852,11 GGCAGGGACATCATGTTCTT & & GTGACTCA \\
\hline Fblim1 & chr4 & 141125723 & 141126527 & 262,92 GCCCAGCACCTTCTGTTCCT & ACCAACCCCACTCC & \\
\hline H6pd & chr4 & 149353543 & 149354307 & 402,8 & ATTTCCCCCACACT & \\
\hline Errfi1 & chr4 & 150155907 & 150156755 & 334,9 & TCCAGCCCCTTCCA & \\
\hline MRPL33 & chr5 & 31936324 & 31937148 & 376,22 TAGAACAGAACATCCCTGGG & & \\
\hline Dok7 & chr5 & 35480489 & 35481131 & 387,2 CAGAGGCACGGAATGTTCCA & & TGAGTCTC \\
\hline Tgfbr3 & chr5 & 107552818 & 107553616 & 351,82 TAAGAGCACTGGCTGTTCTA & TAGGAGGGGCTGGA & ATGACTCA \\
\hline Myo1h & chr5 & 114806421 & 114807295 & 303,27 TGCAGGAATGGTATGTACCC & & \\
\hline Cdk8 & chr5 & 147072041 & 147073399 & 1708,11 & & \\
\hline Hipk2 & chr6 & 38785066 & 38785917 & 297 & & ATTACTCA \\
\hline Tra2a & chr6 & 49186023 & 49186710 & 636,67 & & \\
\hline D6Mm5e & chr6 & 82977753 & 82978472 & 589,14 GCTGGGAACTCCCTGTACTT & & \\
\hline Tead4 & chr6 & 128231964 & 128232801 & 315,09 GCAAAGAACTGTCTGTTCCT & & \\
\hline Hif3a & chr7 & 17643227 & 17644190 & 353,76 GAGGACATTCCGTCCTGTAC & AGGGTGGGGGTAGG & \\
\hline Zfp36 & chr7 & 29160976 & 29161895 & 509,74 CCGCACATTCCGTCCTCGCC & CCCCGCCCCACCCC & \\
\hline Klf13 & chr7 & 71041604 & 71042464 & 1831,31 GGCGGGAACAGCATGTTCTC & TCTTGCCCAAGCCA & \\
\hline $\mathrm{Nr} 2 \mathrm{f} 2$ & chr7 & 77181488 & 77182319 & 277,29 CAAAAGAACAAGCTCTACTT & & CTGACTCA \\
\hline Abhd2 & chr7 & 86481426 & 86482048 & 713,42 AGGAACACCATGTCTTGGAG & & AGTGACTCA \\
\hline AK005418 & chr7 & 117260116 & 117261077 & 278,32 TAGTACATTTTGTACTGTAC & TGGGTGGGGAGAGA & \\
\hline Copb1 & chr7 & 121346072 & 121346998 & 377,11 AGGGAGCACAGTATGTTCCA & & TGAGTAAC \\
\hline Adam12 & chr7 & 141428774 & 141429766 & 412,02 & & \\
\hline Hpgd & chr8 & 58899121 & 58900287 & 352,74 ATGTACATTCTGTTCTATCC & & TGACTCA \\
\hline
\end{tabular}




\begin{tabular}{|c|c|c|c|c|c|c|}
\hline Banp & chr8 & 124551887 & 124552816 & 494,46 AAGAACAGGCTGTGCTTGGT & & TGAGTCAG \\
\hline Cadm1 & chr9 & 47170289 & 47170911 & 709,96 GGCCAGTACAATTTGTTCCT & TGGGAGGGGTTAAA & TGAGGCAG \\
\hline Zbtb16 & chr9 & 48531655 & 48532316 & 626,54 GGCCAGCACTGCGTGTTCCT & & \\
\hline Zbtb16 & chr9 & 48545244 & 48546123 & 357,38 GGGTACAGTGTGTTCTTGGA & & \\
\hline Zc3h12c & chr9 & 51913134 & 51914248 & 461,61 TGCAAGAACCAAATGTTCTC & & CTGACTCA \\
\hline \multicolumn{7}{|l|}{$\mathrm{Rdx}$} \\
\hline Gcnt3 & chr9 & 69895308 & 69896173 & 418,72 TTGTACATGCAGTCCCTGCA & CCCTGCCCAGCCCT & \\
\hline Rpl29 & chr9 & 106314210 & 106315267 & 273,93 & & \\
\hline Cspg5 & chr9 & 110183619 & 110184270 & 474,14 & AGCGTGGGGACCAT & \\
\hline \multicolumn{7}{|c|}{ 2610002I17Rik } \\
\hline Lars2 & chr9 & 123370513 & 123371653 & 1022,6 & & \\
\hline Rap2c & $\operatorname{chrX}$ & 48321683 & 48322064 & 489,34 GACAAGCACAGGCTGTTCTT & & \\
\hline \multicolumn{7}{|l|}{ Frmd7 } \\
\hline |l1rapl1 & chrX & 84483527 & 84484212 & 539,48 & & \\
\hline Tsc22d3 & chrX & 137063416 & 137064179 & 433,76 GCAAAAAACAGAATGTTCAG & AGGGAGGGGCAGGA & TGAGTAAT \\
\hline
\end{tabular}


Sevilla et al., Table S2.

\begin{tabular}{|c|c|c|c|c|c|}
\hline Gene Symbol & Description & Gene Bank & Product (bp) & Forward primer & Reverse primer \\
\hline Per1 & Period circadian clock 1 & NM_001159367.1 & 200 & TACAGGACCGCTGTCGTTGGG & CGTCAAAGCGGAGGCAGGAGG \\
\hline Tsc22d3 & TSC22 domain family, member 3 & 3 NM_001077364.1 & 91 & GGAGGGAATGCAACTGGGAG & ССССTCСCTTGAATGCTGAA \\
\hline Zfp36 & Zinc finger protein 36 & NM_011756.4 & 180 & TCCTCTATCAAGTCCGCCCA & AGGAACGGGATGTTTCCGTC \\
\hline \multicolumn{6}{|l|}{ RT-qPCR } \\
\hline Gene Symbol & Description & Gene Bank & \multicolumn{2}{|c|}{ Product (bp) Forward primer } & Reverse primer \\
\hline Hprt1 (housekeeping) & $\begin{array}{l}\text { Hypoxanthine } \\
\text { phosphoribosyltransferase } 1\end{array}$ & NM_013556 & 142 & TCAGTCAACGGGGGACATAAA & GGGGCTGTACTGCTTAACCAG \\
\hline Klf4 & Kruppel-like factor 4 & NM_010637.3 & 185 & GTGCCCCGACTAACCGTTG & GTCGTTGAACTCCTCGGTCT \\
\hline Nr3c1 & GR alpha & NM_008173.3 & 182 & AAAGAGCTAGGAAAAGCCATTC & CTCAGCTAACATCTCTGGGAATTCA \\
\hline Per1 & Period circadian clock 1 & NM_001159367.1 & 298 & GGGAGACAAGAAGCCCCCGGA & $\triangle$ GTGTCGGCGACCAGGGGGAA \\
\hline Sprr2d & Small proline-rich protein 2d & NM_011470.1 & 336 & TGGTACTCAAGGCCGAGA & TTTGTCCTGATGACTGCTGAAGAC \\
\hline Tsc22d3 (Gilz) & TSC22 domain family, member 3 & 3 NM_001077364.1 & 111 & CTGTTGGCCTCGACTGCTG & GCCGAAAGTTGCTCACGAAG \\
\hline Zfp36 & Zinc finger protein 36 & NM_011756.4 & 112 & CCACCTCCTCTCGATACAAGA & GCTTGGCGAAGTTCACCCA \\
\hline
\end{tabular}


Supplemental Data Legends.

Figure S1. Reduced KIf4 expression in $\mathbf{G R}^{\mathrm{EKO}}$ versus $\mathbf{C O}$ cells. Klf4 expression was assessed in $\mathrm{GR}^{\mathrm{EKO}}$ versus CO cells by RT-QPCR. Mean values $\pm \mathrm{SD}$ are shown, with asterisks denoting statistically significant differences in $\mathrm{GR}^{\mathrm{EKO}}$ relative to $\mathrm{CO}$ (Student's t-test; $\mathrm{n}=3$; *, $\mathrm{p}<0.05$ ).

Figure S2. Evaluation of GR-Klf4 interaction via co-immunoprecipitation. Lysates of cells treated with Dex for 0, 30 or 60 min were subjected to immunoprecipitation with antibody specific for Klf4 or a nonspecific rabbit IgG (t0). Input controls and immunoprecipitates were analysed by immunoblotting with GR, p-GR and Klf4 antibodies.

Table S1. Annotated genes identified by GR ChIP-seq in MPKs after $2 \mathrm{~h}$ of Dex treatment. Gene symbol, chromosomal location (start and end coordinates), p-value, and over-represented GRE, KLF and AP-1 motifs in the genomic sequences are shown.

Table S2. List of primers used for validating the identified GR ChIP-seq targets. 